\title{
From bilingualism to multilingualism in the workplace: the case of the Basque Autonomous Community
}

\author{
Karin van der Worp ${ }^{1} \cdot$ Jasone $_{\text {Cenoz }}{ }^{1}$. \\ Durk Gorter ${ }^{1,2}$
}

Received: 30 December 2015/ Accepted: 13 July 2016/Published online: 16 August 2016

(C) Springer Science+Business Media Dordrecht 2016

\begin{abstract}
In this article we discuss the outcomes of a study into the languages of the workplace of internationally operating companies. Our aim is to contribute to studies of multilingualism in the workplace by adopting a holistic approach that focuses on several languages and relates the competences and attitudes of multilingual professionals to the repertoires used and learned in the workplace and the wider social context. The study is situated in the Basque Autonomous Community, Spain, where the regional government has already developed a strong bilingual language policy to promote the minority language Basque and recently also supports a policy of internationalization of companies, implying the use of other languages. The tensions arising from the confrontation between these two policies are discussed. Based on interviews with 25 informants in managerial positions, we found that the default language of workplace communication is Spanish, there is limited use of Basque and for foreign trade English is dominant, although Spanish is used with Latin America. The language and cultural competence of professionals is lagging behind and should be further developed, although the younger generation has a better command of English. The wider social context has an important influence on the language practices inside the company. Multilingualism plays an important role in Basque companies that operate internationally, but the companies still have to overcome important language barriers. Our study confirms that language practices and language learning experiences are complex and highlights the need for a holistic approach that includes the repertoire of languages used in the workplace.
\end{abstract}

Karin van der Worp

karin.vanderworp@ehu.eus

1 University of the Basque Country, UPV/EHU, Avenida de Tolosa 70, 20018 Donostia-San Sebastián, Spain

2 Ikerbasque, Basque Foundation for Science, Bilbao, Spain 
Keywords Multilingualism · Workplace discourse $\cdot$ Professionals · Basque Autonomous Community

\section{Introduction}

The ever increasing cross border activities of companies (such as selling and buying products or services abroad), the greater mobility of the workforce (for instance growing numbers of expatriates working for a company), and new technologies (like distant communication through the Internet) have all changed today's workplace profoundly. As a consequence many companies and their employees have to deal with different languages on a daily basis. Hence, language policy has, or should, become an important part of how businesses are organized. Multilingualism in the workplace is an area which has gained in interest among researchers (Gunnarsson 2013a; Roberts 2010). An important topic is the study of the language policies and language practices in the workplace, and the disparity between both. The present study aims to explore language policies and language practices in internationally operating companies in the Basque Autonomous Community, a region in Spain with two official languages Basque and Spanish. In this region there is a growing importance of English and thus multilingualism has become an important 'fact of life'. Businesses operate in a social context of two local languages, but have to take other languages into account, in particular in times of economic downturn which has pressured them to internationalize their products.

To place the study in a wider perspective, some previous research will be summarized and a model of multilingualism in the workplace will be developed. The model will guide the analysis of the data obtained through interviews with managers of Basque companies. Our aim is to look into tensions that arise from the confrontation between, on the one hand, a bilingual policy that encourages the use of the minority language, and on the other hand efforts to internationalize companies implying the use of other languages, in particular English, for trade contacts.

\section{Theoretical framework}

Gunnarsson (2013a) provides an overview of many studies about multilingualism in the workplace that have been carried out in recent years. She points to the globalized economy and technological advances as factors that have changed workplace discourse but also to the face-to-face settings of migrant workers who have to master the local majority language. She observes that "language and communication play a more central role today than earlier" (p. 163) and "multilingualism at work thus varies due to position and linguistic and cultural background" (p. 164). She distinguishes two broad categories of multilingual professionals. On one side she places low-paid migrants, who work in entry-level jobs and often need to use a language at work that they do not fully master. On the other side she places welleducated professionals who can move between jobs and countries to improve their 
work life chances and who often are proficient in several languages. These educated professionals can be divided further into two subcategories: professionals who are dislocated from their country of origin and work in another country, and those who work in their home country but use foreign languages at work (see also Day and Wagner 2007, who called them "bilingual professionals"). Our study investigates this subcategory of highly educated professionals who have a job in their home country but who routinely use two or more languages in their workplace.

Gunnarsson (2013a) also presents the model for the contextual analysis of professional discourse (see earlier version in Gunnarsson 2009: 20-27; see also $2013 \mathrm{~b}, 2014)$. The model aims to understand the complex and dynamic relations between workplace discourse and various societal framework systems; it thus takes into consideration the dependence of professional discourse on the wider social context outside the company. Gunnarsson (2009) distinguishes four societal frameworks, each of which she considers to have a specific influence on the professional discourse inside the workplace. The four frameworks are presented in adapted format in Table 1.

We will briefly summarize the four frameworks, (1) technological-economical, (2) legal-political, (3) socio-cultural, and (4) linguistic and we will use them to analyze our own data.

Regarding the technological-economical framework, advances in technology like the Internet and economically driven changes like the globalization of production and of seller-buyer markets, have important influences on activities of professionals and thus on their discourse in the workplace. Also the fact that professionals may have daily contacts in different countries abroad and as a consequence have to use different languages depends on economical circumstances.

The legal-political framework includes political developments and country specific or international legislation, which may concern education, welfare and the media, and to some extent can determine professional discourse. For instance, in the global market, agreements for fewer restraints on trade exercise an influence. Furthermore, the education system, in particular language education, is of importance for professional discourse, as it can create a difference between linguistically skilled and unskilled staff.

Table 1 The four societal frameworks (adapted from Gunnarsson 2009, 2013a)

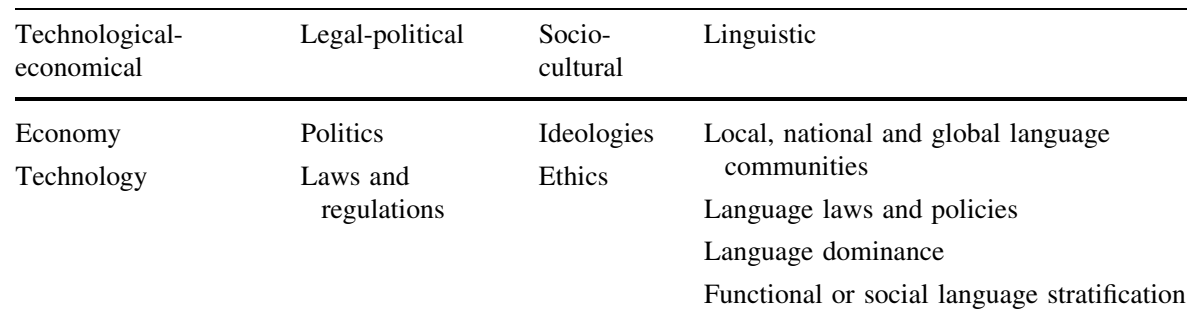


In the socio-cultural framework the culture, ideologies and ethics of a society are reflected in the ethical codes of a professional environment and social values are an essential aspect of professional discourse.

Finally, the linguistic framework refers to language communities, the establishment of language laws and policies, and also power differences between languages and stratification, which all can directly influence text and talk in professions. Language choice in the workplace usually follows the practices in relevant discourse communities. For example, the policies and practices about language issues (for example minority versus majority languages) influence discourse in the workplace, and are commonly reflected in the language knowledge of the participants in professional discourse. Language policy can have an important influence on language developments, in particular when a minority language is involved (Shohamy 2006; Spolsky 2009).

Gunnarsson (2013a) uses her own model to present an overview of studies on multilingualism in workplaces in English-speaking regions categorized according to the well-know division in inner, expanding and outer circles (Kachru 1985). Many studies have been carried out in English-speaking countries, especially in globally operating companies. The European Union also offers opportunities for studies of well-trained professionals and unskilled workers because of many new and more complex multilingual workplaces. The studies she discusses reveal that "a broad spectrum of languages is represented in the daily work-related interaction in multilingual regions in continental and northern Europe", but she does not discuss any studies from southern Europe, so there seems to be a gap. In her recent overview of multilingualism in European workplaces Gunnarsson (2014) briefly mentions a study on Italian and one on Portuguese, but none on Spanish.

Angouri (2013) examines the way language practices are reflected in the language policy of three multinational companies in Europe in a study that combines quantitative questionnaire data with qualitative data from interviews. An advantage of qualitative data is that it can provide deeper and more detailed insights into the role of multilingualism in the workplace. Her data reveal that in these multinational companies the top-down language policies are less important than bottom-up language practices in the communication of teams. These more vague or ambiguous policies are in line with a call for a "flexible" policy and language practices based on a "what works" approach. In another study, Angouri and Miglbauer (2014) interviewed 40 employees in twelve European companies that have English as the corporate language. Their aim was to analyze employees' perceptions of the role of languages in their daily work life. The results indicate that those employees prioritize English, but other languages also play an important role for them. The use of different languages creates a global mindset, but the knowledge of local languages is an important consideration for the integration of foreign employees. In the present study we build on the qualitative approach of Angouri, by taking into account perceptions and experiences from inside the workplace as given by informants in managerial positions. Angouri (2013: 277) also remarks that "research on language policy in complex workplace systems (...) is still relatively scarce" and our study hopes to make a contribution. 
Harzing and her colleagues (Feely and Harzing 2002; Harzing et al. 2011; Harzing and Pudelko 2013) carried out a series of mainly quantitative studies that look into the 'language barrier' in multinational companies, which refers to language differences that lead to communication problems. Feely and Harzing (2002) distinguish three dimensions of the language barrier: (1) language diversity, i.e. the number of different languages the company has to manage; (2) language penetration, i.e. the number of functions engaged in cross-lingual communication; and (3) language sophistication, i.e. the complexity and refinement of the language skills required. They find that the language barrier triggers a range of negative consequences, such as uncertainty, mistrust, conflict and cognitive divides (Feely and Harzing 2002; Tenzer et al. 2013), slowing down and increasing the cost of decision making (Harzing et al. 2011), and leading to communication problems between headquarters and subsidiaries (Harzing and Pudelko 2013). They propose that through linguistic auditing the three dimensions of language diversity, penetration and sophistication can be measured. The authors list a range of other options for companies to overcome the language barrier, among others, the use of external language resources, the provision of training, and selective recruitment of expatriates in management. They highlight that there is no single solution, and problems should be solved depending on the company's context.

Under the auspices of the European Commission, a number of applied studies have been carried out that provide insight into the importance of languages for export and aim at further internationalization of Small and Medium sized Enterprises (SMEs). The European Commission has published a number of reports which are used to raise awareness among the business community that if companies improve their language policies, they can increase their exports. An important example is the ELAN report (European Commission 2006) that gives an account of a survey carried out by CILT, the UK National Centre for Languages. Nearly 2.000 SMEs that are involved in exporting across 29 European states provided data on, among others, language skills and intercultural competence of their employees, their language strategies, and the loss of business owing to lack of languages skills. The report deems it important for companies to have a language strategy, defined as "the planned adoption of a range of techniques to facilitate effective communication with clients and suppliers abroad" (p. 5). The report further indicates that language skills are a key factor in achieving economic growth of companies and that communication problems have financial consequences. According to the survey, $11 \%$ of the SMEs have lost a business contract because of insufficient languages skills. One out of ten European SMEs that operate internationally experience language barriers and intercultural problems when they do business abroad. The report recommends developing adequate language management, in particular to have a written language strategy, to appoint native speakers, to recruit staff with language skills and to use translators or interpreters. In that way companies can create a more successful export performance.

As a follow up to the ELAN study, the European Commission (2011a) published the PIMLICO report, a qualitative investigation of 40 case studies of best practices among SMEs in Europe. The emphasis is again on what are now called Language Management Strategies and the results indicate again that successful international 
companies have various forms of such strategies. Part of those strategies are the capacity to operate in at least three foreign languages, a high level competence in English, the ability to adapt to differing linguistic demands, the use of local agents, and a Human Resources strategy for internationalization, including keeping record of the language abilities of the staff and contracting native speakers. The recommendations seem all fairly common management tools applied to language issues.

Based on the ELAN and PIMLICO reports, the European Commission (2011c) published the Language Guide for European Business. This practical guide was part of an information campaign aimed at improvement of the language management strategies in companies, in particular SMEs. The guide lists several measures that companies can apply in order to become more successful as multilingual companies, similar to the ones mentioned in the recommendations of the ELAN and PIMLICO reports. The European Commission has contracted several other studies in the same area (e.g. European Commission 2010a, b, 2011b) and usually with the same message that more attention to languages leads to better business performance. One recent example is a report on competitiveness of European firms, which signals that a common language is an important driver for internationalization and a lack of foreign language proficiency of the management is an important barrier (European Commission 2014). These applied policy studies can be seen as providing complementary information to more academic investigations of language related issues in multinational companies.

Multilingualism is also an important issue in education. Cenoz and Gorter (2011) have proposed the 'Focus on Multilingualism' as an approach to provide insights into the main principles of multilingualism in educational contexts. Their model builds on and shares characteristics with concepts such as flexible bilingualism (Creese and Blackledge 2010) and translanguaging (Garcia 2009; Garcia and Wei 2014), as it emphasizes the interaction between languages. Their model, with some modifications and adaptations can also be used to analyze the data we obtained for the multilingual workplace. In the Focus on Multilingualism three interrelated dimensions are distinguished: (1) the multilingual speaker, (2) the whole linguistic repertoire and (3) the social context.

The first dimension, the speaker, places the language user at the centre, rather than languages. The multilingual speaker is not considered a monolingual speaker in each of the languages he or she is proficient in, and therefore will not be compared to the ideal native speaker of those languages when speakers learn and use languages. Instead, they are seen as true multilingual speakers with a fluid communicative competence.

The second dimension, the linguistic repertoire, refers to the resources the speaker has available for learning and using languages. It takes into account the complexity of multilingualism and the way the principles and strategies acquired in one language, can support the learning and use of other languages.

The third dimension, the social context, explains that multilingual speakers acquire and use languages while engaging in language practices in a social context. Therefore, when studying multilingualism the influence of the social context should 
be taken into consideration, instead of exclusively focusing on the linguistic dimensions.

Given the importance of the dimension of context, an additional and more detailed approach to context is provided in this paper based on the four societal frameworks of Gunnarsson (2009, 2013a). Her societal frameworks describe the dependence of language use and language learning on the wider context. Our approach is helpful for a better understanding of multilingualism in the workplace of professionals. The model for the study of multilingualism in the workplace is presented in Figure 1.

The three principal dimensions of this model are based on Focus on Multilingualism. Because this approach was developed for educational research, they are adjusted for the study of the workplace. Thus, its three main interrelated dimensions are renamed as: (1) the multilingual professional, an educated professional who has learned several languages, (2) the professional linguistic repertoire, which includes the language practices of professionals in a company and (3) the wider social context, the external circumstances that influence the language practices of the professionals in the company.

Each of the dimensions can be subdivided further. For the multilingual professional, there are two main features: (1) his or her language and cultural competences and (2) his or her language attitudes. The professional linguistic repertoire also has two parts: (1) language practices, that is, all the different languages professionals use in the company and how they use them and (2) their

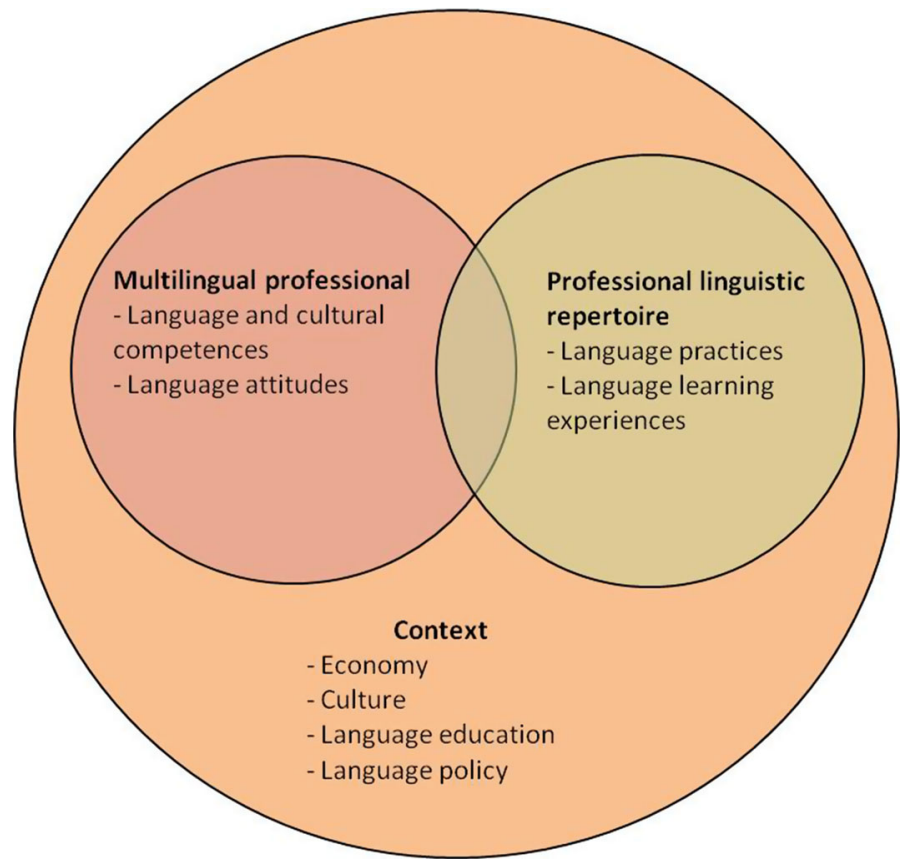

Figure 1 Holistic model of multilingualism in the workplace 
language learning experiences. The context is subdivided further by using the four societal frameworks of Gunnarsson but slightly renamed to serve our purpose. These are (1) economy, (2) culture, (3) language education, and (4) language policy. We are going to use this model to analyze and systematize the data we collected about professionals working in companies in the Basque Autonomous Community.

The aim of this study is to explore multilingualism in the workplace in the Basque Autonomous Community. Our research question is exploratory and departs from our holistic model and it is formulated as follows: What is the role of multilingualism for professionals working in internationally operating companies in a bilingual region?

\section{Setting of the study}

The present study is carried out in the Basque Autonomous Community; this is an administrative area located in the north of Spain, close to the border with France, which has around 2.1 million inhabitants. Today this autonomous community is one of the three administrative parts of the historical Basque Country, which also comprises the Autonomous Community of Navarre in Spain and the Iparralde area in France. In this article we focus only on the Basque Autonomous Community.

In economic terms the Basque Autonomous Community is one of the main industrial areas in Spain, where next to services (68.7 \% of GDP; Eustat 2015: 38), industry is important (23.9\%), especially the technologically advanced light-metal manufacture of machine tools, aeronautics and also energy. The average income is substantially higher than the average for Spain. The economic crisis had a strong impact in Spain and also in the Basque Autonomous Community, but there it had more moderate effects, for example, in terms of unemployment rates: $12 \%$ in the Basque Autonomous Community versus $25 \%$ in Spain as a whole (in 2012). As a reaction to the economic crisis the regional government has developed a strong policy of internationalization for SMEs (Basque Government 2015).

Regarding the linguistic situation since the law of language normalisation of Basque was signed in 1982, both Basque and Spanish are recognized as official languages in the Basque Autonomous Community. Basque is rather distant from Spanish, because it is a non-Indo-European language. The standard variety, known as "Euskara Batua" ("unified Basque"), is used for writing official documents and for language teaching at school. In the Basque Autonomous Community a great effort is being made to protect the language and promote language learning, as the language has a great symbolic value for the Basque citizens (Montrul 2013). Societal bilingualism is the most important aim of language policy, where citizens can freely choose to live through Basque, Spanish or both.

According to the most recent language survey data from 2011, $32 \%$ of the population of 16 years and older are bilingual in Spanish and Basque, $17.4 \%$ are passive bilinguals (only receptive skills in Basque), and 50.6\%-the majority-are monolingual Spanish speakers (Basque Government 2013). Thus Basque in quantitative terms is a minority language, and the socially dominating language is Spanish. 
The last 20 years have seen the gradual introduction of English as a third language at all levels of education (Cenoz 2009; Gorter et al. 2014). This implies a gradual change from a bilingual Basque-Spanish education system where great efforts take place to revive Basque as a 'normal' language of communication, to a system that takes three (or sometimes more) languages into consideration. In the society one can also observe an increase in the diversity of languages and a greater emphasis on English. On the one hand, through a steady influx of migrants from Latin-America, North Africa and many European countries and on the other hand, increased importance given to knowledge of English through the effects of globalization and a successful commercialization of learning English outside school.

\section{Method}

To answer the general research question, a qualitative approach to data collection was adopted for which we used face-to-face interviews. This instrument is considered well-suited to acquire in-depth knowledge of particular multilingual contexts or speakers and to answer complex questions (Codó 2008). During the interviews some basic biographical and relevant background information was obtained, but the emphasis was on views about multilingualism and information about language practices and language learning. The participants are a group of 25 professionals in managerial positions from 14 different companies, all located in the Basque Autonomous Community. The details about the economic sector, the type of company and the job position of the informants are given in Table 2.

The informants all have a high level managerial or directorial position. As can be seen the interviews carried out in 10 of the 14 companies were with one informant. In the other four companies the information had to be obtained from more than one informant because of the way the work was distributed inside the company. In these cases, the information provided by each informant was completed with the additional information provided by other informants from the same company.

As the aim of this exploratory study is to analyze the role of multilingualism for professionals, the companies share two characteristics: they are all related to multilingualism and they belong to different sectors. Regarding multilingualism the companies selected use different languages to different degrees as will be seen later. The companies belong to different sectors: four are Basque internationally operating factories, one is a multinational factory, two are internationally operating service providing companies, three are corporations (two operate internationally, and one focuses on the local market), one is a local language academy and three are consultancy firms (two operate internationally and one focuses on the local market). The choice of these companies is useful for different reasons. A first reason is that it allows us to see both the factories that need multilingualism for internationalization and the language academy and consultancies that provide services to companies to operate internationally. The former can provide direct information about the role of multilingualism in their own company and the latter have the experience of working over recent years with professionals from many other companies. A second reason is 
Table 2 Details about companies and informants interviewed for this study

\begin{tabular}{|c|c|c|}
\hline Sector & Company & Job position of informant \\
\hline \multirow[t]{3}{*}{ Factories } & Factory of metallic parts & $\begin{array}{l}\text { General director } \\
\text { Director of client services } \\
\text { Director of language commission } \\
\text { Human resource manager } \\
\text { Quality manager } \\
\text { Sales manager }\end{array}$ \\
\hline & Factory of professional and industrial tools & $\begin{array}{l}\text { General director } \\
\text { Export manager Asia } \\
\text { Export manager America } \\
\text { Export manager Middle East } \\
\text { Regional manager }\end{array}$ \\
\hline & $\begin{array}{l}\text { Factory of automotive components } \\
\text { Factory of electronics } \\
\text { Factory of adhesive tape }\end{array}$ & $\begin{array}{l}\text { Floor manager } \\
\text { Corporate chief technology officer } \\
\text { Sales manager }\end{array}$ \\
\hline Service providers & $\begin{array}{l}\text { Logistics company } \\
\text { IT service company }\end{array}$ & $\begin{array}{l}\text { Branch manager } \\
\text { Marketing director }\end{array}$ \\
\hline Corporations & $\begin{array}{l}\text { R\&D group } \\
\text { Association of language industries } \\
\text { Business group }\end{array}$ & $\begin{array}{l}\text { Director of international development } \\
\text { General director } \\
\text { Director of co-operative } \\
\text { dissemination }\end{array}$ \\
\hline $\begin{array}{l}\text { Language } \\
\text { academy }\end{array}$ & Language academy & Director of communication \\
\hline \multirow[t]{2}{*}{ Consultancy firms } & Basque consultancy & $\begin{array}{l}\text { Innovation and project manager } \\
\text { Head of consultancy }\end{array}$ \\
\hline & $\begin{array}{l}\text { Internationalization consultancy } \\
\text { Internationalization consultancy }\end{array}$ & $\begin{array}{l}\text { General manager } \\
\text { Internal sales manager } \\
\text { International sales consultant }\end{array}$ \\
\hline
\end{tabular}

that by having different types of companies with different sizes, locations and degrees of internationalization it is possible to identify patterns in the role of multilingualism for professionals that go beyond the study of a specific type of company. Taken together this group of informants presents a solid and extensive understanding of multilingualism and internationalization in the workplace.

Participants were interviewed using a schedule with open questions, and the respondents were given an opportunity to discuss other topics they considered relevant. The guiding questions for the interview included information about the participant and the company, the level of multilingualism of employees, language requirements, cultural differences, language use, language policy and education. In the case of the language academy and the consultancies the information obtained was mainly about the Basque companies they had as clients and their general views on multilingualism in the workplace based on their experience. 
The interviews were held over a time span of half a year, between January 2014 and July 2014. The interviews lasted between 40 and $105 \mathrm{~min}$. Following the recommendations of Codó (2008), the participants were allowed to choose their preferred language for the interview. In our study seventeen participants chose Spanish, and eight preferred Basque. Participants who were proficient in Basque chose Basque to conduct the interview. Six of the 14 companies (two factories, two corporations, the language academy and one consultancy) have taken part in language policy plans to promote the use of Basque. All the participants who chose Basque as the language of the interview came from these six companies which are located in sociolinguistic areas where the use of Basque is more widespread.

The interviews were audio-recorded, while during the interviews additional notes were taken. It was agreed that the identity and location of the companies would remain confidential. All interviews were transcribed and entered in ATLAS.ti (Qualitative Data Analysis software). Free coding was used to structure the content of the interviews. Afterwards, the codes were grouped according to the main features of the holistic model of multilingualism in the workplace.

\section{Results}

In this section we present the outcomes of our data-analysis in order to answer our general research question about the role of multilingualism in internationally operating companies in the Basque Autonomous Community. The presentation will take into account the three main dimensions of the holistic model of multilingualism in the workplace: the multilingual professionals, their linguistic repertoire and the four sub-dimensions of the wider social context. In this exploratory study a qualitative approach based on well informed professionals in different types of companies has been used so as to provide insights and to understand underlying reasons and motivations regarding multilingualism in the workplace in the Basque Autonomous Community.

\section{The multilingual professional}

As we have already seen, the multilingual professional dimension looks at language and cultural competences as well as attitudes. In our study we look at the perceptions that professionals in managerial positions in Basque companies have about language competences in the local languages, Basque and Spanish, as well as in English. Thereafter we examine the attitudes towards multilingualism and towards learning different languages and then we consider the cultural competences of professionals.

Regarding the competences in the two official languages of the region, Basque and Spanish, the interview data reveal that in general all professionals in all fourteen companies can speak Spanish fluently, but not everyone can speak Basque. The head-coordinator of the Basque consultancy firm explains that despite the enormous policy efforts in education, which imply that the overwhelming majority of students nowadays do their primary and secondary studies through Basque, there is still a 
high number of people who do not know Basque at all or only very little. She further points out that among young people this is becoming less and less frequent but (...) one thing is knowledge of the language, and another thing is the use of the language. (...) Understanding a language and being able to have a conversation is something different from feeling comfortable, identifying oneself with the language and choosing to use and live through that language. There is a terrible gap. More than once the participants mention that more Basque is known than is actually used, whereas this is not the case for Spanish. This gap between proficiency and use has also been observed in education, even in Basque medium schools (see Martínez de la Luna et al. 2014).

The foreign language competences of professionals, according to our informants, are mainly limited to English. Skills professionals have in other languages include some mentions of French and German and occasionally Portuguese and Italian. In general, our participants express the idea that professionals are linguistically not well enough prepared to work in other languages than Spanish or Basque, as can be illustrated by the next quote: One thing is talking English, and another thing is doing business in English. Knowing English for going on holiday to London does not mean you can do a business deal of many millions of Euros in English. That is a big step (Head coordinator of Basque consultancy firm). The informants in the five factories, in one service provider company and in one consultancy, however, believe that the language skills of employees in their companies have gotten better over time.

When we asked them to look more closely at the levels of competence in English, the participants hold different opinions about in which professional positions the highest levels of English can be found. Some informants explain that professionals in the departments involved in international trading, usually all can speak English very well. The participants also agree that employees with daily contacts with foreign clients have rather good English language skills. Some informants point out for engineers as a professional category that they usually have good reading skills in English, because they have to be able to understand manuals and technical documentation in English, but their speaking abilities are not necessarily at the same level. Directors of companies usually have a low command of English, according to the informants of the language academy and the Basque consultancy firm. They explain this lack of English competence due to the circumstance that the directors are older on average and in their generation English was not so much required, nor did they learn enough English at school and, due to busy work schedules, it is not easy for them to attend language courses to improve their skills.

All the companies in our study do set language requirements for new job openings. English is in most cases a basic requirement, and some companies also ask for a second foreign language. Basque it not a job requirement in 12 out of the 14 companies, and it is only seen as an additional value. Spanish is taken for granted and thus not even mentioned as a requirement. This demonstrates that one of the aims of governmental language policy, bilingualism in Basque and Spanish as a general requirement, has hardly reached these companies. Other than language skills, the first thing that is usually mentioned as most highly valued is professional knowledge, and employees are not hired just for their language skills. 
In general, participants agree that employees in their companies usually have a positive attitude towards multilingualism in general and also towards people that speak various languages. Attitudes were mentioned by nine companies of all the types and they were always positive. The same companies reported that employees consider multilingualism as something normal and at the same time necessary. If it [learning a language] were as easy as paying money and pressing a button, almost everybody would do so! (Corporate chief technology officer). The reasons given for these positive attitudes were among others, the tendency of young people to travel, for which they need languages, and the influence of new technologies, by means of which English is more and more introduced into the personal lives of employees. Increased travel and new technology have raised the awareness for the need to learn English and sometimes other languages. In the past it was different, as the branch manager of a logistics company explains as follows: When we went to school this was not the case. The other language was another subject (...) and was not seen as necessary. A third language was seen as useless: why would you learn French if you were never going to use it?

Informants from eleven of the fourteen companies mentioned that the job position has an important influence on the attitudes of employees towards language learning. The awareness of a need for language skills is obviously the highest in positions that have more contact with foreigners, and employees in those positions care most about learning languages. The floor manager of a factory affirms that if knowing languages is not part of one's responsibilities, then employees do not see the necessity to improve their language competences. The head coordinator in the Basque consultancy firm also remarks that employees feel more inclined to learn languages if this is remunerated in their salary or gives possibilities for job promotion.

However, the director of international development of a large international $R \& D$ group, despite the positive attitudes towards multilingualism she observed, also saw tensions arising among employees when the company decided to introduce a multilingual policy. According to her, from that moment onwards multilingualism in the workplace became a rather sensitive topic. Professionals who considered Basque as important were afraid that Spanish would begin to dominate but monolingual Spanish speakers thought that all of a sudden they would be obliged to learn other languages, including Basque. She also noticed a utilitarian attitude toward languages when employees considered English more important than Basque, thinking that Basque is not useful for the company, not necessary and not profitable.

When we asked our informants about their personal feelings towards English as a lingua franca, they recognized the efficiency of using a common language. But they also do feel that using only English is not enough. First of all, because there are countries where English is hardly spoken and second, although the professionals of the company abroad may know English, they still appreciate it more when being dealt with in their mother tongue. Knowing other languages than English is seen as a real competitive advantage. This was highlighted by the consultancies and the factories and one of the corporations that work with France, Germany and China. In the third place, as an international consultant explains: The use of English as a lingua franca is also seen by some as a threat to linguistic diversity. 
When we asked them about intercultural competence, all our informants who work for factories that export internationally demonstrate an acute awareness of the importance of cultural differences between countries. They told anecdotes such as In Latin America they can say yes to everything, very kind, but actually they are really not listening to you (Internal sales manager) and The English can be kicking you out, without shouting. They are real gentlemen (Floor manager). Some other informants are more skeptical about the cultural competences, like the director of the association of language industries who firmly states that employees are not sensitive to cultural differences. Also the director of international development, who also has experience in teaching intercultural communication courses, confirms this opinion, when she says that They [the professionals] think they have a lot of cultural sensitivity, but they really have nothing at all. They think it is obvious that Colombians are different [from the Basque] but they don't adapt, they speak the same to them as to someone in a bar in Azpeitia [a Basque village].

The majority of the informants agree that how professionals deal with cultural differences is something that they learn through practice. Only few professionals have the possibility to attend classes or seminars on this topic, and those are usually not organised by the companies where they work.

After looking at the competences and attitudes of the professionals in these Basque companies, we now turn to their repertoire.

\section{The professional linguistic repertoire}

In this section, we focus on the linguistic repertoire of the professionals and we are going to discuss language practices and language learning experiences.

Some use of both official languages Basque and Spanish in companies is common, as our informants confirmed. However, the extent of the use of each language differs widely between companies and their location in different sociolinguistic areas. On the one hand, there is one company where professionals exclusively use Basque as their working language, without using any Spanish for internal purposes. On the other hand, in another company all professionals exclusively use Spanish as their working language. Most companies are somewhere in between, where some of the employees uses both languages in their daily tasks, at least to some degree. Overall, Spanish prevails, if only because not everybody can speak Basque, and in the presence of a non-Basque speaker, a switch to Spanish will almost automatically be made. In formal settings such as meetings Spanish clearly dominates, while in the informal sphere, like chatting with colleagues during coffee break, it is rather common to find both Basque and Spanish. One could conclude that the governmental bilingual policy has led to a general acceptance of Basque for informal work discourse, but has not achieved its aim of 'normalization' of the use of both languages for more formal work related situations.

As far as foreign languages are concerned, English is by far most often mentioned as a language that is more or less frequently used. In fact, the fourteen companies highlighted the importance of English as compared to other languages. Not only for external contacts with countries where English is the official language, but also with other countries like Saudi Arabia, Russia, or China. One informant 
affirms though that in Russia the use of English sometimes causes trouble, because the English level of the Russian partners is usually low. The informant of the language academy refers to communication problems that may arise when two lowlevel speakers of English use functional European English.

In the case of an important export market professionals may try to use the language of the target country. For example, French is mentioned as a language used for trading with France and with certain parts of North Africa, where French is an official language. A few informants also point out that German is used by some Basque companies that trade with Germany. Interestingly, it seems that many professionals prefer to use Spanish when dealing with Italy and Portugal and, of course, especially for contacts in countries in Latin America. Our informants told us that most professionals are aware of some basic differences between Latin American Spanish and Iberian Spanish because it is the same language, but the uses and nuances are different (Marketing director).

For more complex tasks, such as drafting a contract or a business offer in a foreign language, all the companies mention that they outsource the work to a commercial translation service so that their own employees do not have to deal with those tasks is common. It also happens frequently that a professional inside a company has certain language skills, but that those skills are unknown to the management because there is no recording of the employees' language skills in a database. The international consultant actually recognizes that in her work on language policy she discovered valuable language skills among the company's professionals, which were until then unknown to the company.

As far as language learning experiences of multilingual professionals are concerned, we are told by our informants in twelve companies that, although a basic knowledge of foreign language was acquired at school, employers consider the outcome level not sufficient for communicating effectively in the company. Therefore the majority of the professionals have had to increase their language skills necessary for the job after school. Many of them had already chosen to improve their language skills through Erasmus exchanges at university and other stays abroad, but also by taking private classes or in a course at a language academy. Especially, attending language academies is commonplace in the Basque Autonomous Community. We were told more than once that language learning was different for different generations. This is nicely illustrated by a quote from the marketing director of the IT company who is in his late fifties: My grandfather hardly knew any Spanish, he lived on a farm where he spoke Basque and was struggling with Spanish. Then our generation arrived, where there were years when Basque was not allowed to be used, so I didn't learn Basque. When the moment arrived to go to school, I was taught French at school. I started working in French and later, on my own, when working with other providers, I had to learn English.

The professionals practice and maintain their foreign language skills nowadays through daily international contacts, e.g. through the Internet. The director of international development in the $\mathrm{R} \& \mathrm{D}$ group explained that some companies also provide exchange programs with other European places; also the floor manager in a factory of automotive components knew this phenomenon of intra-company exchanges. Although these exchanges are primarily intended to obtain new 
specialized job related skills, on a secondary level, they are also helpful to improve language skills and to practice the use of a foreign language. Many employees also take advantage of language courses that are offered by the majority of the companies, which is common in the Basque Autonomous Community because it started as a grant scheme of the regional government to encourage learning Basque, but now also includes other languages.

However, there are some additional remarks to be made on their experiences with in-company language learning. The head coordinator of the Basque consultancy feels that in-company learning is not satisfactory, A lot of us, who are working nowadays, are learning languages. What I do not see clearly, are the results. We don't set goals, we don't track progress and the learning process, it's like being constantly learning. I'm learning English, I have been learning English for 10 years, but I never finish. It is true that in a way you never stop learning a language, but it is this way of being learning by going to classes all the time. (..) We are going to be attending classes our entire lives. The director of the language academy also believes that only attending language classes at work might not be the best way, and that the lack of language contact outside class hours should be compensated for somehow. Furthermore, busy work agendas and frequent travels are a barrier to language learning at work. This experience is shared by the first author, when she worked as an English teacher in a logistics company. The assistance to the English classes twice a week was often difficult for employees because of work pressure. Many of them frequently arrived late because they had to finish some task, and some had registered but could not attend classes at all. This is also the reason why some professionals do not even start taking a language class: You have to set priorities and they [professionals] don't start to study [because they think] 'when I finish this project, I will start learning the language', and then there comes another project and another one... (Director of co-operative dissemination).

Only two of the companies had a written language policy plan for multilingualism but as it has already been said six companies had a plan for promoting the use of Basque in the company. The employees therefore have to develop a pragmatic strategy every time a language issue comes up, like Let's see, what do you need? French? I have somebody for you (Director of language industries). The professionals inside the company, who master a specific language, are then often resorted to for solving a potential language barrier. However, the way in which this happens is criticized by the director of communication of the language academy who explains her point of view with the following anecdote: If today somebody comes from Massachusetts, to see a machine we have. Gorka knows English, he learned it and got his English certificate and so he will attend to the guest. What is that good for? Is poor Gorka able to do all that work, not only interpreting for the boss, but also transmitting all the values of the company, even if he doesn't know the machine, nor the production? (...) What is failing is that he's not transmitting in an appropriate way and doesn't know the topic well enough. That someone in the company just knows English is not going to help.

Our informants from all the companies taking part in this study agree that outside the school people are hardly exposed to foreign languages, in particular to English, because of the tradition of dubbing into Spanish of programs on television. It 
influences language skills of employees because an important opportunity for language learning gets lost. Even if nowadays, people can opt for seeing programs in their original version on television, this is a very recent phenomenon and only few people seem to use the opportunity. The relatively low level of language skills of employees reflects this lack of opportunities to practice emergent language skills.

\section{The wider social context}

Both the multilingual professional as a person and their linguistic repertoire must be considered in the light of the wider social context, as we outlined in our holistic model of multilingualism in the workplace. We distinguished four main aspects, economy, culture, language education and language policy and our informants also discussed these aspects.

The data from the interviews demonstrate that the recent weakening of the economy of the Basque Autonomous Community, referred to as the economic crisis, has important consequences for internationalization, financial resources and unemployment, which in turn has effects on multilingualism in companies. In fact, this idea is mentioned by the companies that are expanding internationally most recently and the consultancies.

One of the consequences of the economic crisis is an increased need for language skills in the workplace. As the communication director explains, there were mainly small family companies in the Basque Autonomous Community, and those did not have any need to export their products or services because they sold them on the local market. The crisis led to less demand for their products and services and the local market became saturated. Therefore, many small companies started efforts to export their products, for the simple reason that as the sales manager explained, when you can't sell your products here, you have to sell them abroad. The recent export efforts increase the need for communicating in foreign languages and thus somehow for developing a company language policy. According to the internationalization consultant, many companies see their neighbour selling abroad, who then seems to better survive the economic crisis, and thus they want to do the same. However, most of these sudden new export plans are not linked to any language policy and employees are not linguistically prepared.

Half of the participating companies also reveal that to solve possible language problems, some companies that want to internationalize their business, choose to trade with Latin-America, thinking there are no language barriers. The internationalization consultant and the communication director express their criticism about such a choice, because they find that Basque companies underestimate the considerable cultural barriers with Latin American companies. The informants believe that, despite sharing Spanish as a common language, the cultural barrier with such non-European countries might be higher than the language barrier with a culturally closer European country. The regional manager of a company with a lot of experience in trading with Latin America, even questions that there is no language barrier, because he is convinced that Latin American Spanish and Iberian Spanish are rather different. Thinking that working with Latin America has no 
language or cultural barriers, is therefore regarded as erroneous by a majority of our informants.

The economic crisis has also as a consequence to bring out limits on the financial resources of companies. They prioritize their expenses more strictly and do not invest in language policy. The director of international development makes a critical remark about this argument because she believes that the lack of investment in language management is not only due to the recent economic crisis or a lack of financial resources. In her opinion companies have in general been rather reluctant to invest in managing languages because they do not see a clear Return on Investment (ROI). She claims that the ROI seems to be the only powerful reason for companies to justify any investment of time and money: The main concern of the company director is: How can I feed my people at the end of the month? So, how does promoting multilingualism in my company help me to pay the salaries at the end of the month? The majority of our participants believe there is not yet an answer to this question. Calculations as they are given in the ELAN report (European Commission 2006) are not convincing, because they do not show clearly how a loss of money or contracts is directly related to a lack of language policy development.

The economic crisis has also caused a lack of resources for contracting new employees and as a consequence youth unemployment has increased significantly. According to the internationalization consultant, recently graduated students are more likely to possess language skills and thus they could be valuable for companies, but they do not get hired. When those young people with good language skills do not get a job in the Basque Autonomous Community they often decide to work abroad.

The regional culture is another dimension of the wider social context. The informants point out two key aspects of culture in the Basque Autonomous Community that influence multilingualism in the workplace. First, there is a tendency to short term thinking and second, great importance is attributed to having the right connections.

The informants refer to so-called cortoplacismo (short-termism) which is a cultural characteristic that can directly influence language practices in the workplace. This Spanish term relates to the habit of acting on the short term. The general director of the association of language industries explains that companies often only search for ad hoc solutions at the moment they are confronted with a language barrier. The communication director of the language academy adds that the management of companies generally do not feel the need for language learning until the moment they find themselves confronted with situations in which the use of that language is indispensable. Since language learning is a time consuming process, this type of short term thinking does not work.

The propensity to enchufe is a second characteristic of the Basque culture that our informants mention because it can indirectly have an influence on multilingualism. The Spanish word literally means "to plug in" and it concerns the importance of having the right connections or friends in high places to be able to obtain a job position. The way employees are recruited in many Basque companies reflects this cultural trait. The sales manager we interviewed explains that he himself got his job in the company because of the contacts of his family with a person in a high 
position, and not because of his professional qualifications. The relationship between enchufe and language practices in the workplace implies that even if candidates do not have the language requirements for a job they may still obtain the job because of personal contacts.

As the third dimension of the wider social context we distinguish the influence of language education, a factor mentioned by several informants. They made reference to both the quality of language education and to extracurricular language learning. The overall opinion is that education in the Basque Autonomous Community does not prepare students well enough for using foreign languages in their future workplace. Among the diverse reasons given, first of all the didactics of language teaching are criticized. The internal sales manager, who happens also to be a former German teacher, believes that the didactics are not adapted to the age group: Small children have the capacity to learn sounds, and adolescents are able to understand grammar rules, but this is not prioritized in the educational system here in the Basque Country. Various participants bring forward that language is too often taught just as a mere subject, with as only objective to be able to pass exams, which is seen as an academic view on languages, with no or few possibilities to practice the language for communication. The floor manager illustrates this point: The foreign language was just another subject. You could spend 10 years learning French, and ending up without having any clue of French. French used to be the obligatory foreign language at school in the Basque Autonomous Community until it was replaced by English. The result of this change is the existence of three generations of professionals, according to the foreign language they have studied. The oldest generation learned only French at school and no English, the middle generation took classes at the time when French was substituted by English and the youngest generation has only English and no or very little French. According to the branch manager of the logistics company, who is in his late thirties, in his case he started with French and later switched to English, and therefore he acquired neither of the languages sufficiently. The fact that French has disappeared as obligatory foreign language, is mentioned by several other participants, and it causes them great concern, both for ideological and for business reasons. The sales manager expresses his surprise about the fact that French is given so little importance nowadays in the educational system: There are three official languages in the [whole of the] Basque Country, Spanish, Basque and French, shouldn't they all be taught in the Basque Country? Other participants agree that French language skills would be valuable for business, because of the proximity and importance of the French market.

The final contextual factor in our model is the general language policy of the regional government of the Basque Autonomous Community. That policy aims to revitalize the Basque language in all domains of society on the basis of equality of Basque and Spanish. The Basque Government has developed a number of specific language promotional measures for companies. In the first place, already for many years, financial aid is available to promote learning of Basque in companies. Secondly, since 1997 there is an initiative to promote the in-company use of Basque, the so-called LanHitz ("language at work") program. Its aim is to stimulate Basque as a language of the workplace next to Spanish and the program is directly linked to 
the General Plan for the Promotion of the Use of Basque (EBPN 1999). Thirdly, language management of Basque in companies is valued qualitatively and given public recognition through the so-called Bikain ("excellent") certificate. It is annually awarded by Euskalit, the Basque foundation for the promotion of competitive management (Euskalit 2014). As far as foreign language learning is concerned the regional government does have a grant scheme for companies to provide all kinds of training courses to their employees. The scheme consists of general grants for any type of professional education which includes language learning and there are also some specific grants for language learning, including English, French and other languages.

At the same time, the promotion of internationalization of companies is done by the Department of Economic Development and Economic Competition of the Basque government without paying attention to language use or language learning, a circumstance that the two international consultants criticized strongly. They explain that the government produces information guides and organizes workshops or conferences on internationalization, but in there the language component is not or hardly taken into account, even less than the intercultural dimension.

In contrast, the general language policy is carried out by the Department of Education, Language Policy and Culture but the policy restricts itself to BasqueSpanish bilingualism. Some informants consider the bilingual situation of the Basque Autonomous Community a potential advantage for management of multilingualism in the workplace. The general director of the association of language industries explains that companies, whether or not international, are in many cases already used to managing the two official languages, Basque and Spanish, in the workplace. Based on that experience, companies are supposed to be better prepared to manage additional languages. Other participants underline the advantage of being bilingual in regard to language learning and they believe that being bilingual is helpful in learning other languages. The informant of the language academy suggests this might explain the fact that citizens in the Basque Autonomous Community have a higher command of English compared to the rest of Spain.

\section{Discussion and conclusion}

In this study we examine the Basque Autonomous Community, a region where businesses have to take the two official languages Basque and Spanish into account but increasingly also English and other languages. Our aim is to contribute to studies of multilingualism in the workplace by adopting a holistic approach that focuses on several languages and relates the competences and attitudes of multilingual professionals to the repertoires used and learned in the workplace and the social context. Our study is located in a southern European bilingual context in the 'expanding circle' of English but the challenge of the transition from bilingualism to multilingualism can be of interest for other contexts as well.

For many years language policy in the Basque Autonomous Community emphasized the importance of Basque-Spanish bilingualism in order to revive and 
'normalize' the use of the minority language. The government targets its language policy at the broader society and in particular at education, media and the public sector, but it also includes the private sector. In education, language policy has been quite successful and inside the majority of schools a changeover from BasqueSpanish bilingualism to multilingualism adding English and sometimes other languages, has taken place. As we have seen in this study, a similar shift is underway in companies in the region, although for different reasons and at a slower pace. Basque has been introduced in companies little by little, and is now generally accepted as a language of informal communication, even if Spanish continues to dominate workplace discourse. Globalization trends and the recent economic crisis lead to an accelerated internationalization of Basque companies which consequentially leads to the use of English and sometimes of other languages. This situation creates the need to move from bilingualism to multilingualism by bringing together the local and the global.

In order to answer our exploratory research question about the role of multilingualism in internationally operating companies, we have used a model of multilingualism in the workplace based on the Focus on Multilingualism complemented with the four societal frameworks related to workplace discourse of Gunnarsson (2009), where the dependence of professional discourse on the wider social context comes to the foreground. This model is holistic not only because it focuses on several languages but also because it looks at different dimensions of multilingualism in the workplace: individual competences and attitudes, practices and experiences at the workplace and the wider social context.

The first dimension concerns the multilingual professional. In our case this person is an educated professional who has learned several languages, works in the workplace in his or her home country and uses two or more languages on a daily basis. The information given by the 14 companies shows that the language competence of these educated professionals is lagging behind. This is partially a generational issue, but for Basque it is obvious that learning the language at school among the younger generations does not imply automatically using the language for work. For English the younger generations have a better command than the older generation, but the challenge is to reach a level high enough to overcome language barriers and do business successfully (Feely and Harzing 2002) and especially directors of companies seem to lack in sufficient skills. Our study indicates that English is generally a requirement for high-level professionals, but Basque is not, or only from time to time. Most professionals assert positive attitudes towards multilingualism, although there are different opinions on the relative importance of Basque, Spanish and English. Our study shows that the competences and attitudes of multilingual professionals include, but are not limited to, the need to speak English. The multilingual professional needs to develop linguistic and intercultural competences to work in different contexts.

Under the dimension of the linguistic repertoire of professionals we discovered that in terms of language practices some limited use of Basque in companies is common, in particular for informal purposes and one of the factories, some departments of two of the corporations and one consultancy try to do all of their internal business through Basque. Spanish still is usually the default language of 
workplace communication and English is the predominant language for foreign trade contacts, although Spanish with Latin America is widely used and in specific cases also languages such as French or German are mentioned. Language learning at school is not sufficient for the professional workplace and taking additional language courses is common, also in-company courses. The workload, however, often prevents sufficient attendance in such courses which leads to disappointing learning experiences. Our study confirms that language practices and language learning experiences are complex and highlights the need for a holistic approach that includes the repertoire of languages used at the workplace.

The wider social context has an important influence on the language practices in the company. Four aspects were distinguished: the economy, culture, language education and language policy.

The economic crisis has lead to a sudden need for internationalization of some Basque companies because the decline of the sales in Spain since 2009 had to be replaced by other markets. Some companies already worked internationally before the crisis but for others there was no time for proper reflection and planning and limited financial resources for language management. As a result, professionals have to work in an environment with usually no language policy and they try to find pragmatic ad-hoc solutions. This is in line with the observations of Angouri (2013) that instead of a written language strategy, a flexible "what works" approach is adopted.

The cultural context of the Basque Autonomous Community strengthens such pragmatic ad hoc solutions because of the traits of short-term thinking and the tendency to enchufe. These two traits undermine a proper HR-strategy to recruit linguistically skilled employees, a key strategy for language management according to the European Commission (2011a). Apart from that, companies do not prioritize languages in their selection procedures and they do generally not apply any language management strategy such as keeping record of the language abilities of the employees.

At the same time, internationalization and doing business abroad raises the awareness for the need of adequate language skills. However, our informants consider the level of foreign language skills as insufficient, while the European Commission (2006) sees it as necessary to achieve economic growth for a company. Other European recommendations such as the ability to operate as a company in at least three foreign languages are rather seldom fulfilled by Basque companies which mainly rely on English as a lingua franca. There is a little French and German, with which they cannot fully adapt to the language demands of their foreign clients. These results are in agreement with findings of Angouri and Miglbauer (2014). In general employees tend to prioritize English, even if they admit that other languages also play an important role. The majority opts for using English as a lingua franca despite considering it of great importance to speak the language of the client. The head coordinator of the Basque consultancy summarizes the point as we have so many difficulties with English... As we do not fully master English and we need it, we are not able to see that we also need other languages. If we would have had another level of English, for sure we would be able to notice that English is not enough, but as we do not even master English... 
The Basque Government intensively supports internationalization, but it does not focus at the same time much on the language aspect. In contrast, the department responsible for language policy has numerous programs for implementing Basque in the workplace. The formal top-down language policy for the private sector seems less successful than in education which is also related to the need for flexible solutions and a "what works" approach (Angouri 2013). This circumstance reflects the broader context of Basque society, where Spanish is the dominant language and the use of Basque as a minority language is limited, even if it is promoted at all levels of society. English and other languages however, do not have a clear place in society, and the exposure to English and other languages is limited. Developments in education emerge as a key factor that creates a generational divide between French and English language skills in the staff and determines to an important extent the level of language competences. According to the informants the level obtained through formal education is not sufficient and the level of competence in English reached is not high enough. Many employees therefore have chosen to complement their language learning in institutions outside the school. The interaction of economic, cultural, educational and language policy factors creates new situations and increases the need to move from bilingualism to multilingualism in the workplace. The context of this study shows that there are tensions between the new opportunities to advance multilingualism in the workplace and the constraints to develop the use of some languages. There are more opportunities than in the past to develop the use of Basque and English but at the same time the use of these languages in the workplace is limited by the minority status of Basque, the limited exposure to English or ineffective cultural practices.

The results also show there are still some language barriers (Feely and Harzing 2002), mainly in terms of language diversity which involves the use of three and sometimes more languages, and of language sophistication, which has to be seen as a lack of required language skills. The professionals have to deal with a number of languages in their daily work and most of them have to get better at that. The complexity of language competences forms another main language barrier in the companies. Feely and Harzing (2002) have a point when they highlight that there is no single solution, and problems should be solved depending on the company's context.

We can conclude that the three dimensions of the model are intertwined: the language competences and attitudes of the multilingual professionals shape their language practices and language learning and vice versa, and the social context has an important influence on both. This interaction between the three dimensions of the holistic model of multilingualism in the workplace reported in this study refers to a specific context and a specific repertoire of languages but can be extended to other situations as well.

Multilingualism does play an increasingly important role in Basque companies that operate internationally, but the companies still have to overcome important language barriers. They have to, and want to, deal with multilingualism but there still is a long way to go to develop and improve the language policies of companies. 
Acknowledgments This work was supported by the Basque Department of Education, Research and Universities [IT-362-10 (UFI 11/54)] and the Zabalduz program of the University of the Basque Country $\mathrm{UPV} / \mathrm{EHU}$

\section{References}

Angouri, J. (2013). The multilingual reality of the multinational workplace: Language policy and language use. Journal of Multilingual and Multicultural Development, 34(6), 564-581. doi:10.1080/ 01434632.2013 .807273

Angouri, J., \& Miglbauer, M. (2014). And then we summarise in English for the others: The lived experience of the multilingual workplace. Multilingua-Journal of Cross-Cultural and Interlanguage Communication, 33(1-2), 147-172. doi:10.1515/multi-2014-0007.

Basque Government. (2013). Fifth sociolinguistic survey 2011. Vitoria- Gasteiz: Vice-ministry for language policy Basque Government. Online at: www.euskara.euskadi.eus/contenidos/informacion/ sociolinguistic_research2011/en_2011/adjuntos/FithSociolingusticSurvey.pdf

Basque Government. (2015). Política de internacionalización. Website at: http://www.industria.ejgv. euskadi.eus/r44-de0017/es/contenidos/informacion/presentacion_intern/es_intern/pol_inter.html

Cenoz, J. (2009). Towards multilingual education: Basque educational research from an international perspective. Bristol: Multilingual Matters.

Cenoz, J., \& Gorter, D. (2011). Focus on multilingualism: A study of trilingual writing. The Modern Language Journal, 95(3), 356-369. doi:10.1111/j.1540-4781.2011.01206.x.

Codó, E. (2008). Interviews and questionnaires. In L. Wei \& M. Moyer (Eds.), The Blackwell guide to research methods in bilingualism and multilingualism (pp. 158-176). Malden, MA: Blackwell Publishing.

Creese, A., \& Blackledge, A. (2010). Translanguaging in the bilingual classroom: A pedagogy for learning and teaching? The Modern Language Journal, 94, 103-115.

Day, D., \& Wagner, J. (2007). Bilingual professionals. In P. Auer \& L. Wei (Eds.), Handbook of multilingualism and multilingual communication (pp. 391-404). Berlin: Mouton de Gruyter.

EBPN. (1999). Plan General de Promoción del Uso del Euskera. Vitoria-Gasteiz: Servicio Central de Publicaciones del Gobierno Vasco. Online at: http://www.euskara.euskadi.eus/r59-733/es/ (in Spanish).

European Commission. (2006). ELAN: Effects on the European economy of shortages of foreign language skills in enterprise. Manchester, United Kingdom: CILT.

European Commission. (2010a). Working group "Languages for Jobs": Providing multilingual communication skills for the labour market. Online at: http://ec.europa.eu/languages/policy/ strategic-framework/documents/languages-for-jobs-report_en.pdf

European Commission. (2010b). Internationalisation of European SMEs (Final Report). Brussels: European Commission. Online at: http://ec.europa.eu/DocsRoom/documents/10008/attachments/1/ translations/en/renditions/pdf

European Commission. (2011a). Report on language management strategies and best practice in European SMEs: The PIMLICO project. Luxembourg: Publications Office of the European Commission. Online at: http://ec.europa.eu/languages/policy/strategic-framework/documents/ pimlico-full-report_en.pdf

European Commission. (2011b). Mapping best multilingual business practices in the EU. Luxembourg: Publications Office. doi:10.2782/4316 Online at: www.termcoord.eu/wp-content/uploads/2013/08/ Mapping_best_multilingual_business_practices_in_the_EU.pdf

European Commission. (2011c). The language guide for European business. Successful communication in your international trade. Luxembourg: Publications Office. doi:10.2766/91001 Online at: http:// bookshop.europa.eu/en/the-language-guide-for-european-business-pbNC3110923/

European Commission. (2014). Drivers of SME internationalisation: Implications for firm growth and competitiveness. Luxembourg: Publications Office. Online at: http://bookshop.europa.eu/en/driversof-sme-internationalisation-pbNB0614003/

Euskalit (2014). Bikain. Online at https://www.euskalit.net/bikain/erderaz.php

Eustat (2015). Anuario estadístico Vasco 2015. Online at http://eustat.eus/document/epubs/publicaciones/ anuario2015_c/index.html 
Feely, A. J., \& Harzing, A. (2002). Language management in multinational companies. Cross Cultural Management: An International Journal, 10(2), 37-52. doi:10.1108/13527600310797586.

García, O. (2009). Bilingual education in the 21st century: A global perspective. Malden, MA: Blackwell.

Garcia, O., \& Wei, Li. (2014). Translanguaging: Language, bilingualism and education. Basingstoke, UK: Palgrave Macmillan.

Gorter, D., Zenotz, V., Etxague, X., \& Cenoz, J. (2014). Multilingualism and European minority languages: The case of Basque. In D. Gorter, V. Zenotz, \& J. Cenoz (Eds.), Minority languages and multilingual education: bridging the local and the global (pp. 278-301). Berlin: Springer.

Gunnarsson, B. (2009). Professional discourse. London: Continuum Discourse Series.

Gunnarsson, B. (2013a). Multilingualism in the workplace. Annual Review of Applied Linguistics, 33, 162-189. doi:10.1017/S0267190513000123.

Gunnarsson, B. (2013b). Multilingualism at work. The encyclopedia of applied linguistics (1-9). New Jersey: Blackwell Publishing. doi:10.1002/9781405198431.wbeal0807

Gunnarsson, B. (2014). Multilingualism in European workplaces. Multilingua-Journal of Cross-Cultural and Interlanguage Communication, 33(1-2), 11-33. doi:10.1515/multi-2014-0002.

Harzing, A., Köster, K., \& Magner, U. (2011). Babel in business: The language barrier and its solutions in the HQ-subsidiary relationship. Journal of World Business, 46(3), 279-287. doi:10.1016/j.jwb.2010. 07.005 .

Harzing, A., \& Pudelko, M. (2013). Hablas vielleicht un peu la mia language? A comprehensive overview of the role of language differences in headquarters-subsidiary communication. The International Journal of Human Resource Management, 24, 1-22. doi:10.1080/09585192.2013.809013.

Kachru, B. B. (1985). Standards, codification and sociolinguistic realism: the English language in the outer circle. In R. Quirk \& H. G. Widdowson (Eds.), English in the world: Teaching and learning the language and literatures (pp. 11-30). Cambridge: Cambridge University Press.

Martínez de Luna, I., Zalbide, M., Darquennes, J., \& Suberbiola, P. (2014). The use of Basque in model D schools in the Basque Autonomous Community. European Journal of Applied Linguistics, 2(2), 254-286. doi:10.1515/eujal-2013-0013.

Montrul, S. (2013). El bilingüismo en el mundo hispanohablante. Malden, MA: Wiley.

Roberts, C. (2010). Language Socialization in the workplace. Annual Review of Applied Linguistics, 30, 211-227. doi:10.1017/S0267190510000127.

Shohamy, E. (2006). Language policy: Hidden agendas and new approaches. New York: Routledge.

Spolsky, B. (2009). Language Management. Cambridge: Cambridge University Press.

Tenzer, H., Pudelko, M., \& Harzing, A. (2013). The impact of language barriers on trust formation in multinational teams. Journal of International Business Studies, 45, 508-535. doi:10.1057/jibs.2013. 64.

Karin van der Worp holds a cum laude international doctoral degree from the University of the Basque Country in Donostia-San Sebastián, Spain and is a member of the research group Donostia Research on Education and Multilingualism (DREAM). Her current work examines multilingualism in the workplace. Her research interests include multilingualism in the workplace, minority languages and foreign language acquisition. She holds a master's degree in teaching Spanish language and culture as well as a cum laude master's degree in applied linguistics, from the University of Groningen in the Netherlands. Furthermore, she has experience in teaching Spanish as a foreign language and writing Spanish course books.

Jasone Cenoz is Professor of Research Methods in Education at the University of the Basque Country. She is the President of the International Association of Multilingualism. Her research focuses on multilingual education, bilingualism and multilingualism. Her publications include Teaching through Basque (2008 as a special issue of Language, Culture and Curriculum), The Multiple Realities of Multilingualism (co-edited with Elka Todeva), Towards Multilingual Education (2009, Spanish Association of Applied Linguistics 2010 award) and Focus on Multilingualism in School Contexts (2011, co-edited with Durk Gorter as a special issue of the Modern Language Journal). She is the coordinator of the European Master in Multilingualism and Education (EMME): http://www.ehu.eus/en/ web/mastermultilingualeducation. 
Durk Gorter is Ikerbasque research professor at the University of the Basque Country, Spain. He is the head of the Donostia Research group on Education And Multilingualism (DREAM). He does research on multilingual education, European minority languages and linguistic landscapes. Among his recent publications are, Minority Languages in the Linguistic Landscape (2012, co-edited with Heiko Marten and Luk Van Mensel), Minority Languages and Multilingual Education: Bridging the Local and the Global (2014, co-edited with Victoria Zenotz and Jasone Cenoz) and Multilingual Education: Between language learning and translanguaging (2015, co-edited with Jasone Cenoz). He also teaches in the European Master in Multilingualism and Education (EMME). 